\begin{tabular}{|cc|}
\hline MONOTERPENES & OXIDATION \\
REARRANGEMENT & TENAX \\
PINENES & $p$-CYMENE \\
THIOSULPHATE & CARBONATE \\
SAMPLING & ANALYSES \\
\hline
\end{tabular}

Open access manuscript version of Journal of Chromatography 589 (1992) 385-389 Link to publisher: doi:10.1016/0021-9673(92)80051-U

\title{
Protection of terpenes against oxidative and acid decomposition on adsorbent cartridges
}

Ann-Margret Strömvall and Göran Petersson

Applied studies of terpene emissions were made for $\underline{\text { TMP and sulphite pulp mills }}$

Kraft pulp mills 


\title{
Protection of terpenes against oxidative and acid decomposition on adsorbent cartridges
}

\author{
ANN-MARGRET STRÖMVALL AND GÖRAN PETERSSON \\ Department of Chemical Environmental Science \\ Chalmers University of Technology \\ 41296 Göteborg (Sweden)
}




\begin{abstract}
Sampling of monoterpenes from air on the Tenax porous polymer may introduce analytical errors owing to oxidation and acid rearrangements on the adsorbent. Particularly terpenes which react rapidly with ozone, e.g. myrcene and limonene, are partially lost when sampling air with high photooxidant levels. On acidified adsorption cartridges, $\alpha$-pinene and $\beta$-pinene may be converted to camphene, limonene, $p$-cymene and several minor monoterpenes.

Pretreatment of the adsorbent cartridges with thiosulphate as an anti-oxidant and bicarbonate as a buffer were found to prevent decomposition and rearrangements. Applications to monoterpenes emitted from kraft, thermo-mechanical, and sulphite pulp industries are presented.
\end{abstract}




\section{INTRODUCTION}

Sampling of organic air pollutants on adsorbent cartridges is a widely applied technique because of its simplicity and versatility. It suffers, however, from the inherent disadvantage that adsorbed compounds may react with each other and with active species from the air, passing through the cartridge [1]. The very front of the adsorbent column is particularly susceptible to reactions because of elevated levels of all compunds adsorbed. Reactive agents in air may also affect the adsorbent, and thiosulphate treatment was early introduced to protect Tenax cartridges [1, 2].

Among the hydrocarbons, the terpenes are exceptionally reactive towards air pollutants such as photooxidants [3]. The atmospheric chemistry and the environmental impact of terpenes are subjects of great current interest. A favoured technique for sampling of terpenes in air is adsorption on the Tenax porous polymer. Our contributions include studies of monoterpenes from pine forests [4], logging operations [5], and pulp industries [6]. Throughout, a key to reliable results was found to be the presently reported techniques for avoiding decomposition and rearrangements in the adsorption cartridges. 


\section{EXPERIMENTAL}

\section{Basic analytical system}

The adsorption cartridges were $80 \times 2.2 \mathrm{~mm}$ i.d. glass liners filled with 0.1-0.2 $\mathrm{ml}$ of the Tenax adsorbent (60-80 mesh). Field samples were taken by connecting the cartridges to conventional portable air sampling pumps [2]. The air volumes were typically in the range of $0.2-2$ litres.

In the laboratory, thermal desorption was effected in the injector of a conventional gas chromatograph [2].The oven temperature was kept below zero during desorption and raised $2^{\circ} \mathrm{C} / \mathrm{min}$ during analysis. The analytical column was a $25 \mathrm{~m} \times 0.33 \mathrm{~mm}$ i.d. fused silica capillary with the cross-linked methylsilicone BP-1 as the stationary phase. Detection was by flame ionization and the same response factor was used for all monoterpenes.

\section{Treatments of adsorbent cartridges}

The Tenax adsorbent was kept in place by two glass pellets made from fritted glass filters, with a minimal amount of silanized glass wool providing the required friction between the pellets and the wall of the glass liner.

A 5\% aqueous solution of $\mathrm{Na}_{2} \mathrm{~S}_{2} \mathrm{O}_{3}$ was used for anti-oxidant treatment. A droplet $(10-20 \mu \mathrm{l})$ was introduced onto the front of the adsorbent layer using a micropipette. The water was evaporated at an elevated temperature and the cartridge preconditioned in the GC injector before sampling.

Pretreatment with $\mathrm{NaHCO}_{3}$ as a buffer against acids was made in an analogous manner with a $5 \%$ aqueous solution. 


\section{RESULTS AND DISCUSSION}

\section{Oxidative decomposition}

In Table I, results are given for samples taken at ground level several hundred meters downwind of two pulp mills. The kraft mill was Gruvöns Bruk, northwest of lake Vänern, with terpene emissions mainly from processed Scots pine. The thermo-mechanical pulp (TMP) mill was Bravikens Pappersbruk, in Norrköping on the east coast, with terpene emissions almost exclusively from processed Norway spruce. The samples taken on Tenax cartridges pretreated with thiosulphate correctly reflect the monoterpene composition, as confirmed by comparisons with many other samples. The differing composition of monoterpenes from the two mills reflect the caracteristic differences between Norway spruce with large proportions of $\alpha$-pinene and $\beta$-pinene, and Scots pine with large proportions of $\alpha$-pinene and 3-carene [5].

For duplicate samples, taken with untreated cartridges, the percentual oxidative losses given in Table I were observed. It is seen that $\beta$-pinene and the terpene-related alkylbenzene $p$-cymene are not affected, whereas the acyclic trienic myrcene is lost completely. The other major monoterpenes were lost to varying degrees from the fairly stable $\alpha$-pinene to the reactive limonene. The same order of reactivity was observed on other occasions for several different untreated duplicate cartridges, although the degree of losses varied. The greatest losses were observed during daytime in the summer, in periods of fine weather favouring high levels of photooxidants.

Ozone is a major photooxidant which may cause losses, owing to the high reactivity of ozone with branched alkenes such as terpenes. From Table I, it is evident that the gas-phase reactivity of terpenes with ozone correlates fairly well with the sampling losses of different terpenes. Accordingly, sampling of monoterpenes with and without an ozone scrubber [7] results in differences similar to those observed with and without thiosulphate treatment. It should be remembered, however, that terpenes react rapidly with other photooxidants as well, and that decomposition in the front of the adsorption cartridges is not a gas-phase reaction.

Freshly thiosulphate-treated cartridges normally permitted satisfactory recovery of myrcene, thus ensuring that no oxidative losses of the less reactive monoterpenes were obtained. The minor monoterpenes terpinolene, $\alpha$-terpinene and $\alpha$-phellandrene are even more reactive than myrcene with ozone [3], but they are often absent in ambient air owing to their high gas-phase reactivity. Near conifers and anthropogenic monoterpene emissions, they act as oxidant scavengers and may be sampled without oxidative losses [5].

Oxidative reactions during sampling also affect the Tenax adsorbent and cause the formation of artifacts such as benzaldehyde and acetophenone [2]. The 
TABLE I

OXIDATIVE DECOMPOSITION ON TENAX ADSORPTION CARTRIDGES. AMBIENT MONOTERPENE SAMPLES TAKEN IN PULP MUL PLUMES.

\begin{tabular}{|c|c|c|c|c|c|}
\hline & $\begin{array}{l}\text { Kraft mill, } \\
8 / 17 / 90,10\end{array}$ & $\begin{array}{l}\text { Scots pine } \\
0.15-12.15\end{array}$ & $\begin{array}{r}\text { TMP mill, } \\
8 / 21 / 90\end{array}$ & $\begin{array}{l}\text { Norway spruce } \\
11.15-13.00\end{array}$ & $\begin{array}{l}\text { Reaction rate } \\
\text { with ozone in air [3] }\end{array}$ \\
\hline & $\begin{array}{c}\mathrm{Na}_{2} \mathrm{~S}_{2} \mathrm{O}_{3} \\
\mu \mathrm{g} / \mathrm{m}^{3}\end{array}$ & $\begin{array}{l}\text { untreated } \\
\text { \% loss }\end{array}$ & $\begin{array}{c}\mathrm{Na}_{2} \mathrm{~S}_{2} \mathrm{O}_{3} \\
\mu \mathrm{g} / \mathrm{m}^{3}\end{array}$ & $\begin{array}{l}\text { untreated } \\
\% \text { loss }\end{array}$ & $\begin{array}{c}\mathrm{k} \times 10^{17} \\
\mathrm{~cm}^{3} \text { molecule }^{-1} \mathrm{~s}^{-1}\end{array}$ \\
\hline$p$-cymene & 0.75 & 0 & 0.28 & 0 & $<0.005$ \\
\hline$\beta$-pinene & 6.4 & 0 & 10.6 & 0 & 1.5 \\
\hline$\alpha$-pinene & 33.9 & 6 & 23.8 & 6 & 9.7 \\
\hline 3-carene & 13.9 & 34 & 2.3 & 33 & 5.2 \\
\hline$\beta$-phellandrene & 0.80 & 55 & 1.2 & 63 & 17 \\
\hline limonene & 1.70 & 76 & 1.7 & 80 & 21 \\
\hline myrcene & 0.33 & 100 & 0.22 & 100 & 49 \\
\hline
\end{tabular}


thiosulphate treatment prevents this decomposition and therefore often provides additionally improved analytical quality.

\section{Acid rearrangements}

In Table II, the percentual monoterpene composition is given for emission samples from the processing of spruce pulpwood. The first sample corresponds to TMP refiner steam emissions passed through fresh chips before venting to air at the Braviken mill. The sample from industrial pulpwood chipping was taken at the Billerud sulphite pulp mill west of lake Vänern. It is seen that the percentual compositions are very similar. In Fig. 1, the chromatographic separation is illustrated. The total monoterpene concentrations were as high as $7 \mathrm{mg} / \mathrm{m}^{3}$ for the TMP sample and $60 \mathrm{mg} / \mathrm{m}^{3}$ for the chipping sample. As a consequence, even the most easily oxidized hydrocarbon monoterpenes could be determined without oxidative losses. The minor species $\alpha$-phellandrene and $\alpha$-terpinene are just visible in the front of 3-carene and p-cymene in Fig. 1, with the attenuation chosen.

The duplicate samples in Table II were taken on cartridges acidified by trace amounts of sulphuric acid. No significant decrease of the total amount of monoterpenes was observed, but the composition was very different, indicating acid rearrangements in the acidified cartridges. The proportions of $\alpha$-pinene and particularly $\beta$-pinene were greatly lowered and those of $\beta$-phellandrene and 3-carene were somewhat lowered. The percentages of camphene, limonene, terpinolene and the alkylbenzene $p$-cymene were much higher. The minor cyclohexadienic components $\gamma$-terpinene, $\alpha$-terpinene and $\alpha$-phellandrene increased remarkably compared to their true proportions in the emissions. Other samples taken on acidified cartridges were found to give qualitatively the same errors although the magnitude and proportions of the deviations varied.

The basic acidic rearrangement reactions of monoterpenes, as outlined in Fig. 2, are well compatible with the deviations observed for acidified cartridges. The acid rearrangements of $\alpha$-pinene and $\beta$-pinene to camphene, and via the depicted carbonium ion to isomerizing monocyclic terpenes, are known from terpene chemistry $[8,9]$. The formation of $p$-cymene in high yield from monoterpenes is also known from the acid sulphite pulping process [10]. The deviations for intermediate terpenes like limonene were found to be of an irregular magnitude for different acidic samples. Weakly acidified samples tended to give rerrangements without any significant dehydrogenation to $p$-cymene. The danger of overlooking more or less subtle analytical errors resulting from acid rearrangements is obvious.

The pretreatment of the adsorption cartridges with buffering bicarbonate prevented acid rearrangements without deteriorating analytical performance. After this treatment, the acidified cartridges worked perfectly well again. Reproducible results could be obtained even for digester emissions from the acid sulphite pulp 
ACID REARRANGEMENTS ON TENAX ADSORPTION CARTRIDGES. PERCENTUAL COMPOSITION OF MONOTERPENES EMITTED FROM WOOD OF NORWAY SPRUCE.

\begin{tabular}{|c|c|c|c|c|c|}
\hline & \multirow[t]{2}{*}{ Structure } & \multicolumn{2}{|c|}{ TMP process } & \multicolumn{2}{|c|}{ Pulpwood chipping } \\
\hline & & Correct & Acidic & Correct & Acidic \\
\hline$\alpha$-pinene & & 58 & 55 & 58 & 46 \\
\hline$\beta$-pinene & & 26 & 14 & 23 & 12 \\
\hline camphene & & 1.7 & 6.1 & 1.8 & 9.0 \\
\hline 3-carene & & 3.5 & 3.3 & 4.9 & 4.2 \\
\hline$\beta$-phellandrene & & 3.0 & 2.9 & 3.1 & 2.3 \\
\hline limonene & & 5.1 & 9.9 & 6.2 & 9.3 \\
\hline terpinolene & & 0.25 & 1.3 & 0.40 & 2.2 \\
\hline$\gamma$-terpinene & & 0.10 & 0.6 & 0.11 & 1.1 \\
\hline$\alpha$-phellandrene & & 0.05 & 0.5 & 0.07 & 0.5 \\
\hline$\alpha$-terpinene & & 0.04 & 0.6 & 0.06 & 1.1 \\
\hline$p$-cymene & & 0.8 & 3.3 & 0.9 & 8.6 \\
\hline
\end{tabular}


mill. It is emphasized that most anthropogenic terpene emissions from forestry and the forest industry are accompanied by emissions of acidic sulphur and nitrogen oxides as well as organic acids. The acidity of ambient air in general is well known. The pretreatment of adsorption cartridges with a buffer may therefore offer an improved analytical quality for a wide range of applications.

\section{REFERENCES}

1. J.E. Bunch and E.D. Pellizzari, J. Chromatogr., 186 (1979) 811.

2. M. Mattsson and G. Petersson, Int. J. Environ. Anal. Chem., 11 (1982) 211.

3. R. Atkinson, D. Hasegawa and S.M. Aschmann, Int. J. Chem. Kinet., 22 (1990) 871.

4. G. Petersson, Atmos. Environ., 22 (1988) 2617

5. A.-M. Strömvall and G. Petersson, Scand. J. For Res., 6 (1991) 253.

6. A.-M. Strömvall and G. Petersson, Holzforschung, 44 (1990) 449.

7. F. Jüttner, J. Chromatogr., 442 (1988) 157.

8. S. Coffey (Editor), Rodd's Cemistry of Carbon Compuonds IIc, Elsevier, Amsterdam, 1969.

9. G.N. Valkanas, J. Org. Chem., 41 (1976) 1179.

10. A. Waller, Sven. Papperstidn., 44 (1941) 427. 


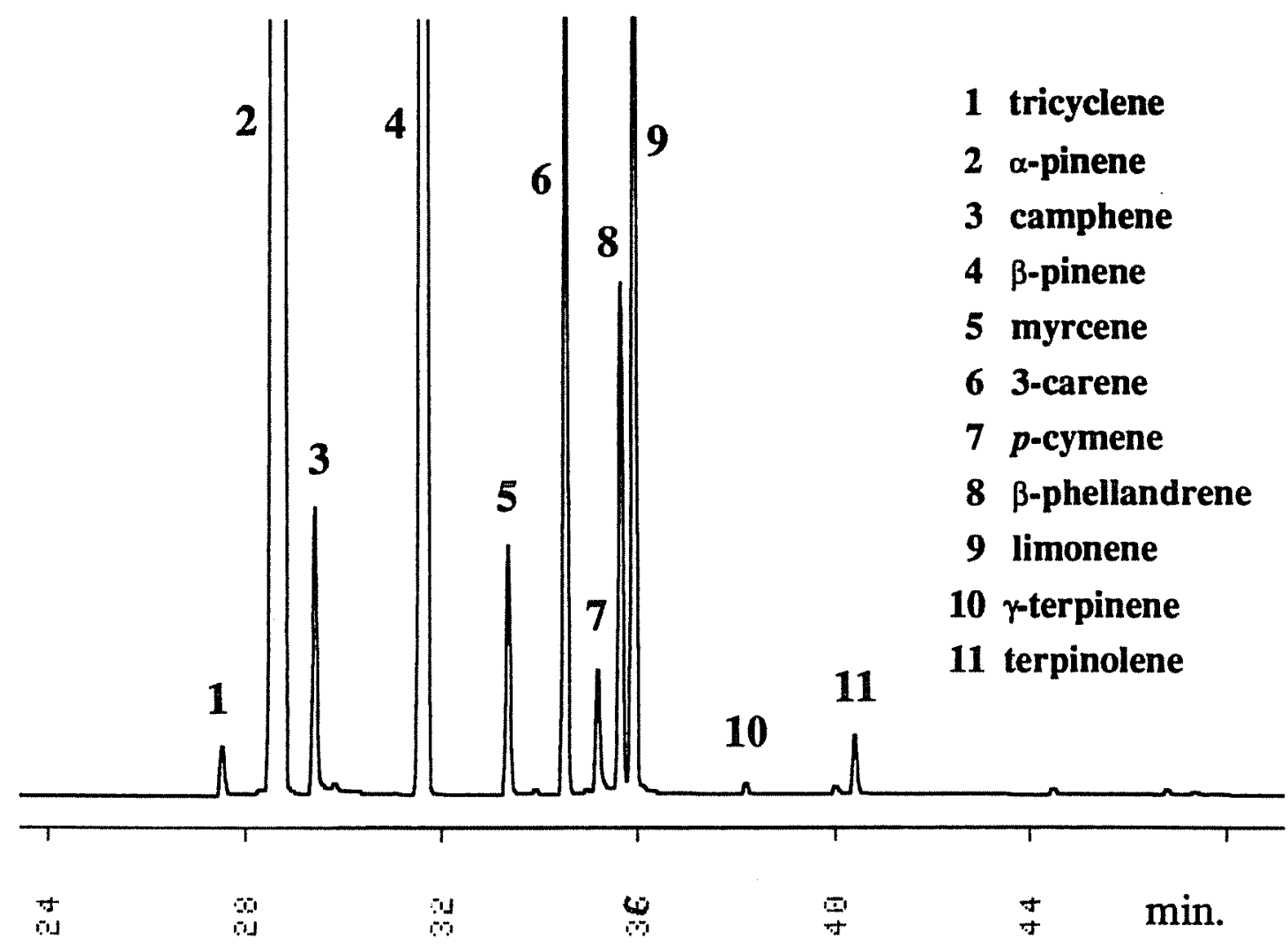

Fig 1. Gas chromaotgraphic separation of monoterpenes from spruce pulpwood chipping. 


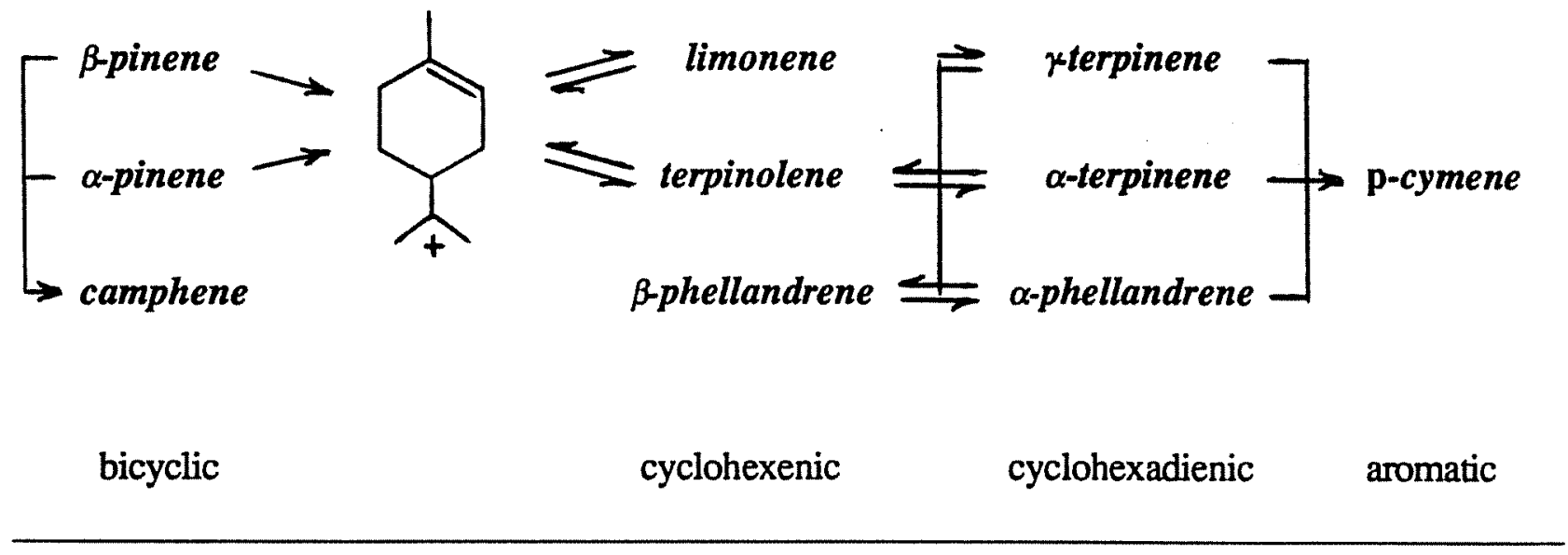

Fig. 2 Scheme of sequencial acid-catalyzed rearrangements of monoterpenes 